\title{
Simulation Model of Shipboard Low Voltage Molded Case Circuit Breaker Based on PSCAD/EMTDC
}

\author{
Jing Huang, Bing Shen, Feng Yang \\ College of Electrical Engineering, Naval University of Engineering, Wuhan, China \\ Email: hjing99421@126.com
}

Received December 2013

\begin{abstract}
A simulation model of shipboard low voltage molded case circuit breaker (MCCB) is developed based on power system simulation software PSCAD/EMTDC. The motion characteristic of the magnetic instantaneous acting trip based on electromagnetic characteristic analysis and Cassie arc model are applied into the simulation model to describe the dynamic behavior of the MCCB during short-circuit protection. The results of short-circuit interruption experiments verify the simulation model. It demonstrates that the simulation model has good prospect in optimizing the design and protection performance of MCCB.
\end{abstract}

\section{Keywords}

Shipboard Power System; MCCB; Dynamic Behavior; Arc Model; PSCAD/EMTDC

\section{Introduction}

Low voltage molded case circuit breakers (MCCB) are widely applied in shipboard power system. The protection characteristics of MCCB are in close relation to power supply reliability of important shipboard loads which have great effect on the safety of navigation. It is necessary to analyze the dynamic characteristic of MCCB during short circuit protection, and build corresponding simulation model, so that the design and protection parameters setting of MCCB can be optimized.

The process of breaking short circuit current is a complex physical process which coupled with mechanical movement, electric circuit, magnetic field and electric arc. And the protection characteristics of MCCB are mainly depending on the mechanical movement characteristic of magnetic trip and dynamic characteristic of arc. So there are many papers which discuss the mathematic model of magnetic trip [1]-[4] and arc [5]-[8].

In this paper, the mathematical models of instantaneous acting trip and switching arc are firstly studied. The characteristic of electromagnetic torque on armature in the trip which varied with the current and air gap is analyzed using ANSOFT. The analysis results are integrated with mechanical motion equations and arc model to build a simulation model of MCCB based on PSCAD/EMTDC. Short-circuit interruption experiments are carried out to verify the simulation model.

How to cite this paper: Huang, J., Shen, B. and Yang, F. (2014) Simulation Model of Shipboard Low Voltage Molded Case Circuit Breaker Based on PSCAD/EMTDC. Journal of Power and Energy Engineering, 2, 532-540. 


\section{Mathematical Models of MCCB}

\subsection{3-D Model of Instantaneous Acting Trip in MCCB}

Take a typical shipboard low voltage molded case circuit breaker whose rated current is 400A for example, the 3-D model of its instantaneous acting magnetic trip is shown in Figure 1. This is typical clapper trip without iron core. The main magnetic path is comprised by yoke and armature. An irregular shaped conductor pass through the yoke and armature.

\subsection{Motion Equation of the Instantaneous Acting Trip}

It can be seen from Figure 1 that when current flow through the conductor, an electromagnetic torque on armature will be generated. The effect of the electromagnetic torque is to spin the armature in the decrease direction of air gap. Meanwhile, counter torque on the armature will prevent rotation of armature. So the motion equation of the armature can be written as

$$
\left\{\begin{array}{l}
\frac{\mathrm{d} \omega}{\mathrm{d} t}=\frac{1}{J}\left[T_{e}-T_{f}\right] \\
-\frac{\mathrm{d} \theta}{\mathrm{dt}}=\omega
\end{array}\right.
$$

where $\theta$ is the angle between the yoke and armature shown in Figure 2, $\omega$ is angular velocity of armature, $T_{e}$ is the electromagnetic torque, $T_{f}$ is the counter torque, and $J$ is rotation inertia of armature.

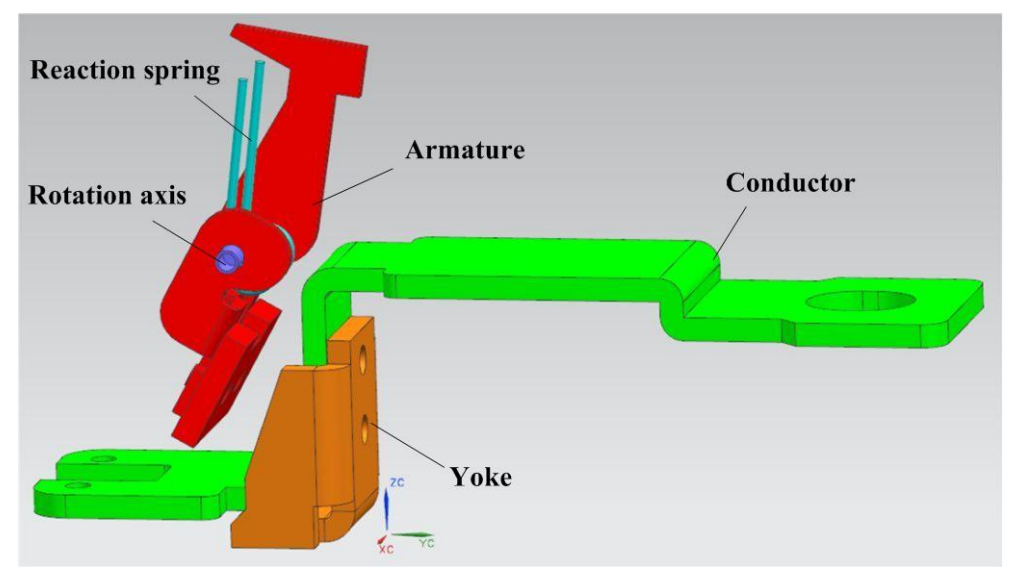

Figure 1. 3-D model of instantaneous acting trip in 400A molded case circuit breaker.

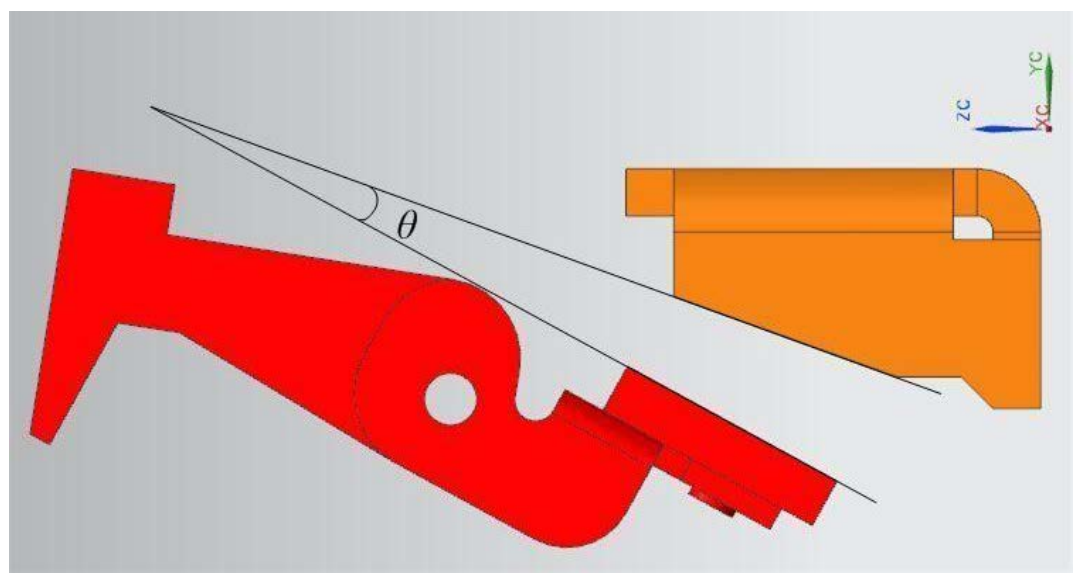

Figure 2. The angle $\theta$ between armature and yoke. 
The counter torque is made up of three parts which are torque of reaction spring, frictional resistance moment, and trip torque. The trip torque is the reaction torque when armature knocks the tripping shaft which will then trigger the actuating mechanism to pull apart main contact of circuit breaker. So the trip torque works when the armature rotates at a certain angle range in which the armature has contact with tripping shaft. The counter torque can be written as

$$
T_{f}=\left\{\begin{array}{lr}
M\left(\theta_{\max }-\theta+\theta_{0}\right)+T_{m} & \left(\theta_{\min } \leq \theta<\theta_{1}\right) \\
T_{r}+M\left(\theta_{\max }-\theta+\theta_{0}\right)+T_{m} & \left(\theta_{1} \leq \theta \leq \theta_{2}\right) \\
M\left(\theta_{\max }-\theta+\theta_{0}\right)+T_{m} & \left(\theta_{2} \leq \theta \leq \theta_{\max }\right)
\end{array}\right.
$$

where $M$ is rigidity of torsion spring, $T_{m}$ is the frictional resistance moment, $T_{r}$ is the average trip torque which can be obtained by experiment, $\theta_{\max }$ is the maximum value or initial value of $\theta, \theta_{\min }$ is the minimum value of $\theta$, $\left[\theta_{1}, \theta_{2}\right]$ is the angle range of armature in which the trip torque works.

\subsection{Mathematical Model of Arc}

For the area of arc model, there are two classical black-box mathematical models: Mayr model defined by Equation (3) and Cassie model defined by Equation (4).

$$
\begin{aligned}
& \frac{1}{g} \frac{d g}{d t}=\frac{1}{\tau_{m}}\left(\frac{u \cdot i}{P}-1\right) \\
& \frac{1}{g} \frac{d g}{d t}=\frac{1}{\tau_{c}}\left(\frac{u^{2}}{U_{c}^{2}}-1\right)
\end{aligned}
$$

where $g$ is the conductance of arc, $u$ is the arc voltage, $i$ is the arc current, $\tau_{m}$ and $\tau_{c}$ are the time constant defined by Mayr model and Cassie model respectively, $P$ is the radiating power of arc, $U_{c}$ is the arc voltage gradient.

Previous study shows that Cassie's equation describes an arc more clearly for the high currents and Mayr's equation when close to current zero [5]. The short circuit currents are much high in shipboard power system due to low voltage and short cables. Meanwhile, we pay more attention to the movement process of armature before knocking the tripping shaft, and the short circuit currents are still high during the process. So we decided to use the Cassie model to describe the arc characteristic.

\section{Analysis on Electromagnetic Character-Istic of Instantaneous Acting Trip}

To simulate the dynamic behavior of the instantaneous acting trip based on the motion equation mentioned above, the variable $T_{e}$ needs to be accurately calculated. So the 3-D model of trip shown in Figure 1 is imported into the finite element calculation software ANSOFT, and the electromagnetic characteristics of the instantaneous acting trip are analyzed using transient response solver of ANSOFT. Figure 3 shows the distribution of magnetic induction density vector in armature and yoke of trip calculated by ANSOFT when the excitation current through the conductor is up to $55.2 \mathrm{kA}$.

As we know, the induction density and the electromagnetic torque of the armature are mainly depend on the excitation current and air gap between the yoke and armature. And the air gap can be measured by the angle $\theta$. So the electromagnetic torques $T_{e}$ under different current of conductor $i$ and angle $\theta$ are calculated using ANSOFT. The calculation results are shown in Figure 4. The angles shown in Figure $\mathbf{4}$ are rotation angles in the increase direction of $\theta$, and negative angles means the decrease of $\theta$ and air gap.

It can be seen from Figure 4 that $T_{e}$ increases with the increase of $i$ and the decrease of $\theta$. The sample points of $T_{e}$ will provide interpolation data for simulation model of circuit breaker.

\section{Simulation Model for MCCB}

\subsection{Simulation Model for Instantaneous Acting Trip}

Based on the motion equation of armature defined by Equation (1) and the characteristic of electromagnetic torque on the armature, a simulation model for the instantaneous acting trip is built by using PSCAD/EMTDC simulation software which is shown in Figure 5. 


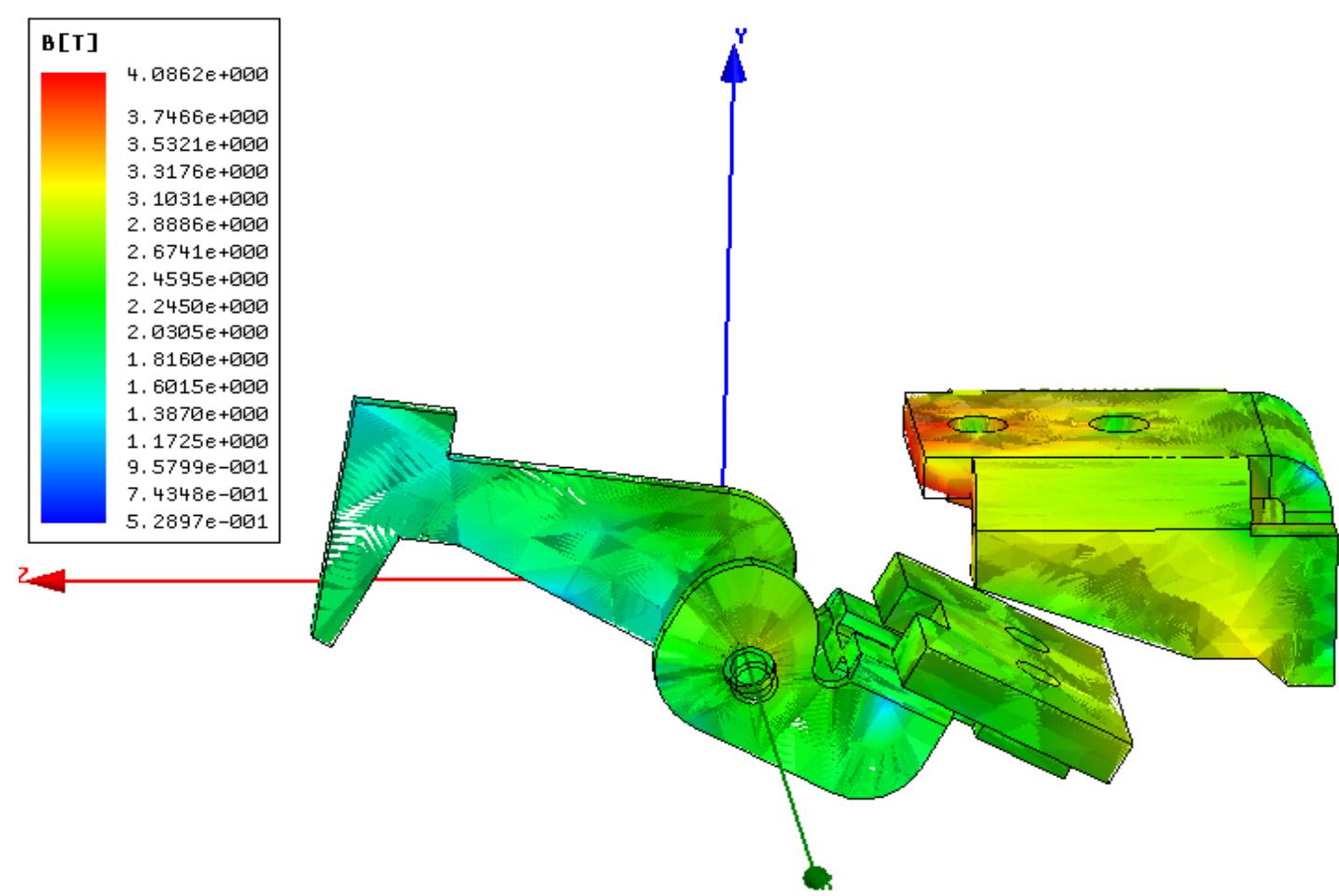

Figure 3. Distribution of magnetic induction density of armature and yoke ( $i=55.2 \mathrm{kA})$.

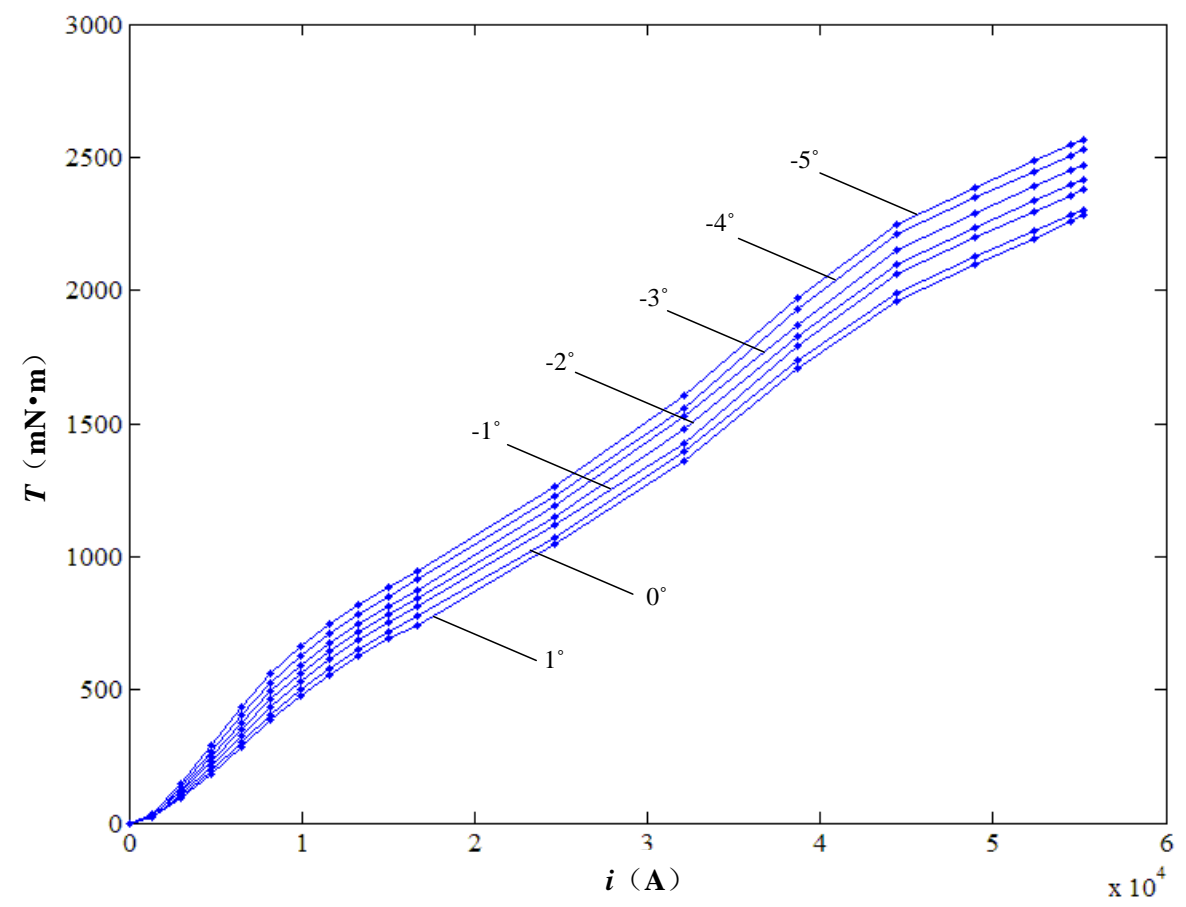

Figure 4. Electromagnetic torque on armature varied with current and air gap.

It can be seen from Figure 5 that the differential operators in the Equation (1) are transformed into two integrating elements in the simulation model. The user defined module "Te_400A" is used to calculate the electromagnetic torque on the armature during simulation processes which store the data of electromagnetic torque shown in Figure 4 in the form of a two-dimensional array. The current $i$ and the air gap angle $\theta$ are taken as in- 


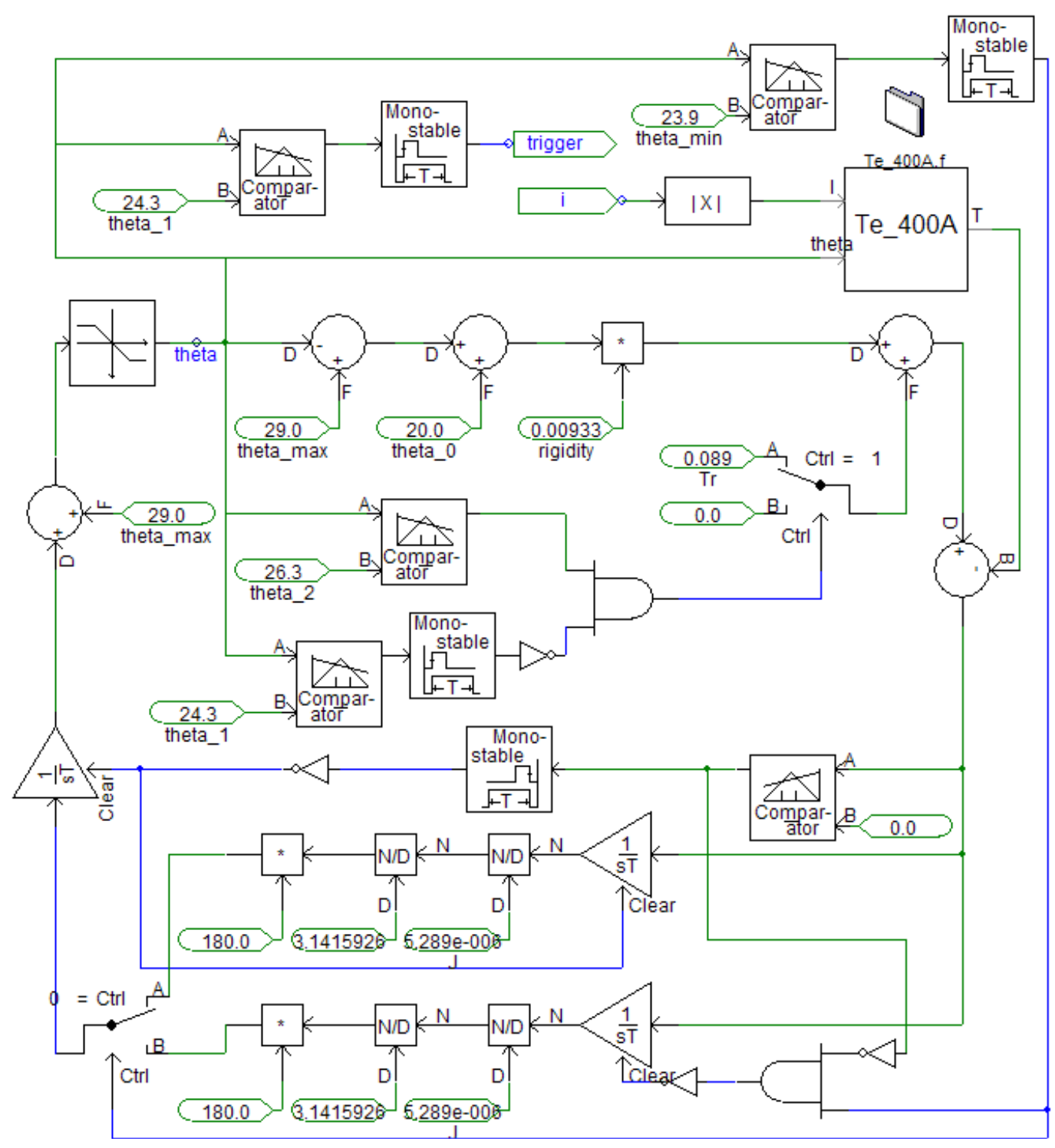

Figure 5. Simulation model for instantaneous acting trip.

put of the module, and the electromagnetic torque can be obtained by interpolation calculation for the two-dimensional array based on the dual three-opint interpolation formula which can be written as

$$
T_{e}(\theta, i)=\sum_{m=p}^{p+2} \sum_{n=q}^{q+2}\left(\prod_{\substack{k=p \\ k \neq m}}^{p+2} \frac{\theta-\boldsymbol{\theta}(k)}{\boldsymbol{\theta}(m)-\boldsymbol{\theta}(k)}\right)\left(\prod_{\substack{l=q \\ l \neq n}}^{q+2} \frac{i-\mathbf{I}(l)}{\mathbf{I}(n)-\mathbf{I}(l)}\right) \mathbf{T}_{e}[\boldsymbol{\theta}(m), \mathbf{I}(n)]
$$

where $\boldsymbol{\theta}$ is the one-dimensional array of air gap angle $\theta, \boldsymbol{I}$ is the one-dimensional array of current $i$, and $\boldsymbol{T}_{\boldsymbol{e}}$ is the two-dimensional array of the electromagnetic torque.

When the current $i$ is high enough so that the electromagnetic torque is greater than initial reaction torque, the armature begins to rotate and the air gap angle $\theta$ decrease. When $\theta$ is lesser than $\theta_{2}$, the trip torque $T_{r}$ starts to take effect to the armature. When $\theta$ is lesser than $\theta_{\min }$, the trigger signal will be send out, the circuit breaker will be tripped and switching off. The process that actuating mechanism pulls apart main contact of circuit breaker is relative shorter than tripping action, and can be simulation using delay module. The trip simulation models for each phase simulate the dynamic behavior of trips in corresponding phase, and any trip reach the tripping condition, the trigger signal will be send out. 


\subsection{Simulation Model for Switching Arc}

Based on the Cassie arc model, a simulation model for switching arc is built by using PSCAD/EMTDC which is shown in Figure 6.

The simulation model for arc contains three user defined module “Cassie_Arc_Model” which are used to simulate the equivalent impedance of arc for each phase. The three modules are actually controllable impedance models whose impedance are controlled by solving the Cassie arc model defined by Equation (4) at each time step after receives the trip signal. The implicit trapezoidal method [9] is applied to transform the Equation (4) into differential equation which can be written as

$$
\frac{g(t+\Delta t)-g(t)}{\Delta t}=\frac{1}{\tau_{c}}\left[\frac{u^{2}(t+\Delta t)+u^{2}(t)}{2 U_{c}^{2}}-1\right] \cdot \frac{g(t+\Delta t)+g(t)}{2}
$$

So the conductance of arc at next simulation step can be obtained as

$$
g(t+\Delta t)=\frac{4 \tau_{c} U_{c}^{2}-2 \Delta t U_{c}^{2}+\Delta t\left[u^{2}(t+\Delta t)+u^{2}(t)\right]}{4 \tau_{c} U_{c}^{2}+2 \Delta t U_{c}^{2}-\Delta t\left[u^{2}(t+\Delta t)+u^{2}(t)\right]} g(t)
$$

where $u(t+\Delta t)$ is voltage of arc at next time step which can be obtained by the predictor formula shown as following

$$
u(t+\Delta t)=1.33 u(t)-0.66 u(t-\Delta t)+0.33 u(t-2 \Delta t)
$$

The conductance is calculated according to the differential equations until the arc extinguishes. In this case, the peak value of the arc resistance for the model is set to a very high value (in our model, $10^{6} \Omega$ ) to representing the open circuit breaker.

\section{Verification of the Simulation Model}

To verify the simulation model, an experimental system for short circuit breaking test was built. The schematic diagram of the experimental system is shown in Figure 7.

The short circuit current peak value in the short circuit test without the test MCCB was set to 199 kA by adjusting controlled reactors. The instantaneous action current of the test MCCB was set to 10 times of rated current. Figure 8 shows the three phase current waveforms of the short circuit current breaking experiment for the MCCB.

A simulation system was built exactly according to the experimental system. The expected short circuit current peak value in the simulation system was also set to $199 \mathrm{kA}$. The motion parameters of the simulation model for the test MCCB are shown in Table 1.

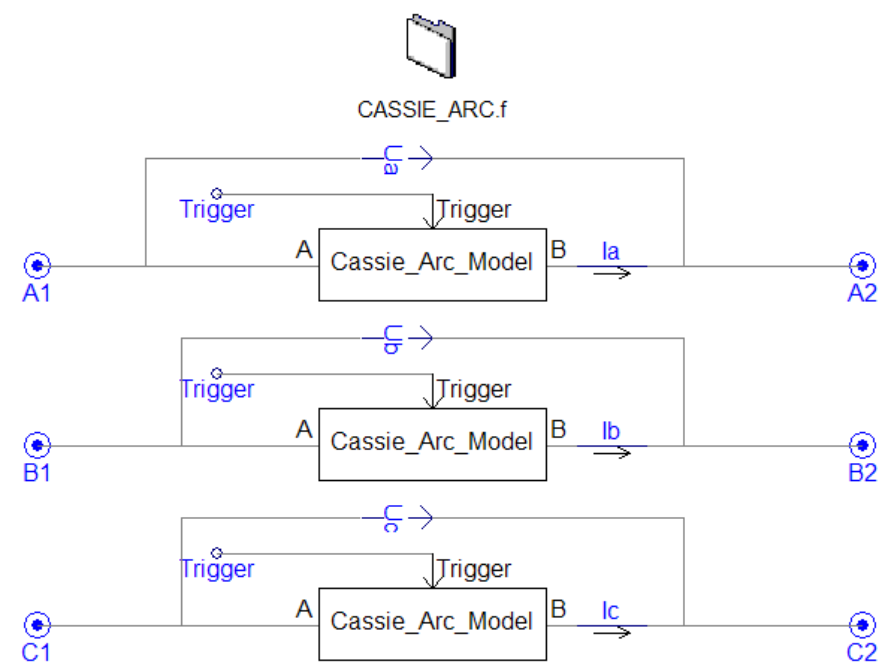

Figure 6. Simulation model for Switching Arc. 


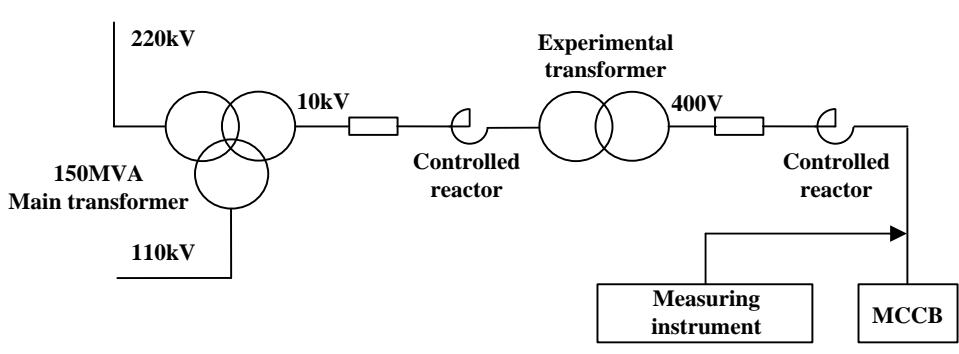

Figure 7. Schematic diagram of experimental system.

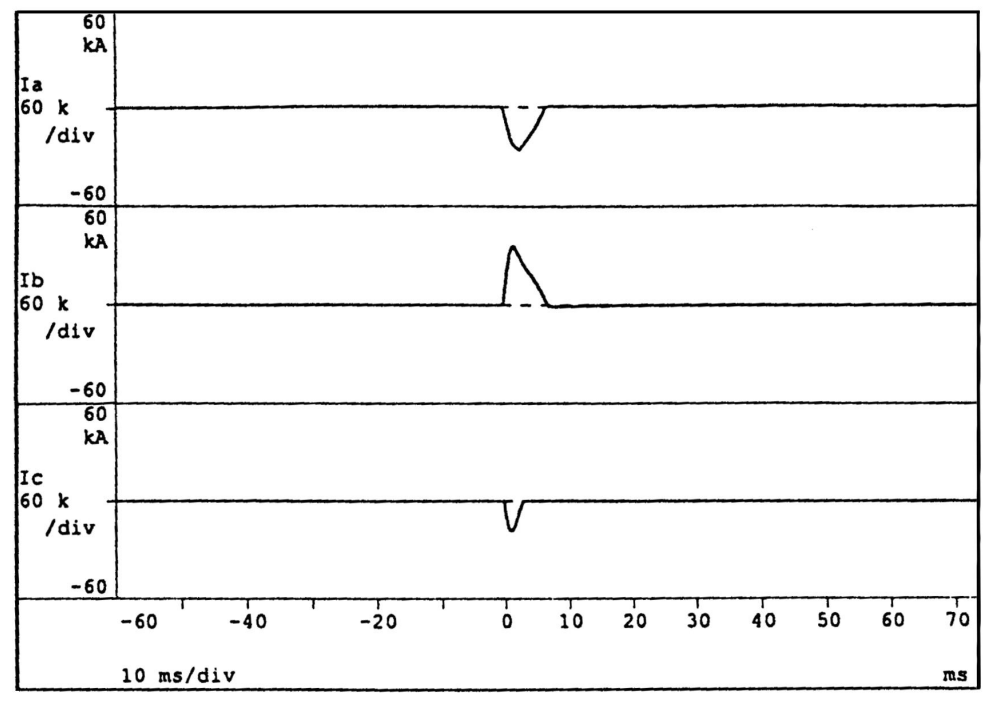

Figure 8. Three phase current waveforms of the short circuit current breaking experiment for the MCCB.

Table 1. Parameters of the motion equation of armature.

\begin{tabular}{cccc}
\hline Parameters & Value & Parameters & Value \\
\hline$M(\mathrm{~N} \cdot \mathrm{mm} /$ degree $)$ & 9.33 & $\theta_{0}$ (degree) & 20.0 \\
$J\left(\mathrm{~kg} \cdot \mathrm{m}^{2}\right)$ & $5.289 \times 10^{-6}$ & $\theta_{1}$ (degree) & 24.3 \\
$\theta_{\max }($ degree $)$ & 29.0 & $\theta_{2}$ (degree) & 26.3 \\
$\theta_{\min }($ degree $)$ & 23.9 & $T_{r}(\mathrm{~N} \cdot \mathrm{m})$ & 0.089 \\
\hline
\end{tabular}

The used parameters of the arc model were adjusted several times to match the test MCCB which were: $\tau_{m}=$ $1.5 \times 10^{-4}$ s and $U_{c}=350 \mathrm{~V}$.

Figure 9 shows the three phase current waveforms of the short circuit current breaking simulation for the MCCB.

It can be seen form Figures 8 and $\mathbf{9}$ that there is a good correlation between simulation and experiment measurement. Table 2 shows the comparison of simulation results with experiment.

It can be seen form Table 2 that the relative errors between simulation and experiment measurement are all less than $9 \%$ which demonstrates that the proposed simulation model has good veracity in simulating the dynamic behavior of MCCB during short-circuit protection.

\section{Conclusion}

A simulation model for MCCB which couples dynamic processes of mechanics, electromagnetic and switching arc has been developed by embedding some self-programmed simulation modules into the simulation software 


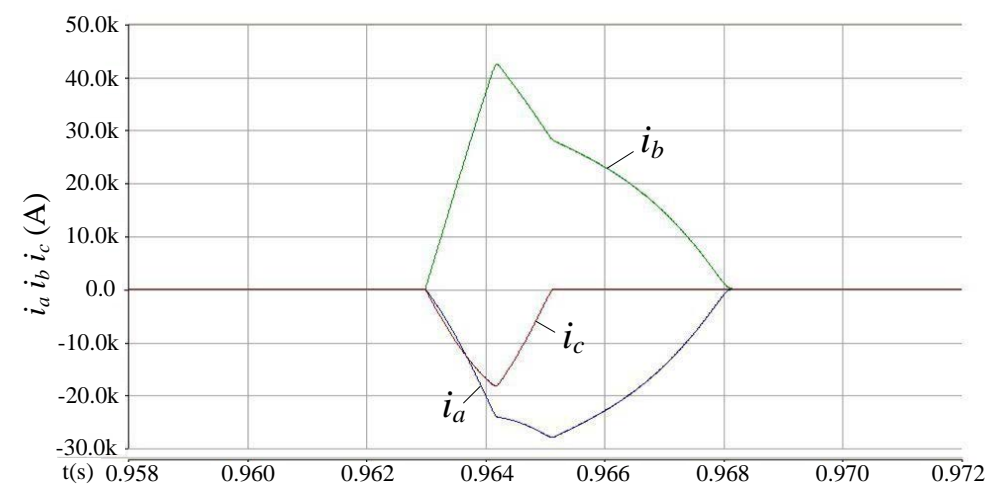

Figure 9. Three phase current waveforms of the short circuit current breaking simulation for the MCCB.

Table 2. Comparison of simulation results with experiment.

\begin{tabular}{|c|c|c|c|c|c|}
\hline \multirow{2}{*}{$\begin{array}{l}\text { Short circuit } \\
\text { characteristic }\end{array}$} & \multicolumn{3}{|c|}{ Short circuit current peak value (kA) } & \multirow{2}{*}{$\begin{array}{l}\text { Duration of } \\
\text { short-circuit }\end{array}$} & \multirow{2}{*}{$\begin{array}{c}\text { Arc } \\
\text { duration }\end{array}$} \\
\hline & $\left(i_{p}\right)_{a}$ & $\left(i_{p}\right)_{b}$ & $\left(i_{p}\right)_{c}$ & & \\
\hline Experiment & 25.8 & 35.7 & 18.2 & 5.93 & 4.72 \\
\hline Simulatioin & 25.2 & 38.8 & 17.1 & 5.42 & 4.32 \\
\hline Relative error & 2.3 & 8.7 & 6.0 & 8.6 & 8.5 \\
\hline
\end{tabular}

PSCAD/EMTDC. The relative errors between simulation and experiment measurement are less than $9 \%$ which demonstrate that the model is accurate enough to describe the dynamic behavior and protection feature of the MCCB. The simulation model for MCCB can be directly used in the simulation program based on PSCAD/ EMTDC. So simulation programs for different shipboard power systems which contain multiple machines, complex distribution network and multiple circuit breakers can be built. It will be useful to evaluate the protection performance of the power system by short-circuit interruption simulations which can then be optimized by adjusting protection parameters setting of circuit breakers.

\section{Acknowledgements}

This work was supported by the National Natural Science Foundation of China (NSFC) under Grant 51207165.

\section{References}

[1] Kawase, Y., Mori, H. and Ito, S. (1997) 3-D Element Analysis of Electrodyanmic Repulsion Forces in Stationary Electric Contacts Taking into Account Asymmetric Shape. IEEE Transactions on Magnetics, 33, 1994-1999. http://dx.doi.org/10.1109/20.582692

[2] Tto, S. and Takato, Y. (1998) Numerical Analysis of Electromagnetic Forces in Low Voltage AC Circuit Breakers Using 3-D Finite Element Method Taking into Account Eddy Currents. IEEE Transactions on Magnetics, 34, 2597-2600. http://dx.doi.org/10.1109/20.717600

[3] Stammberger, H. (1998) Force Calculation for the Movable Contact of Circuit Breakers. Proceedings of the 19th International Conference on Electric Contact Phenomena, Nuremberg, 14-17.

[4] Atienza, E., Perrault, M. and Wurtz, F. (2000) A Methodology for the Sizing and the Optimization of An Electromagnetic Release. IEEE Transactions on Magnetics, 36, 1659-1663. http://dx.doi.org/10.1109/20.877761

[5] Bizjak, G., Zunko, P. and Povh, D. (1995) Circuit Breaker Model for Digital Simulation Based on Mayr's and Cassie’s Differential Arc Equations. IEEE Transactions on Power Delivery, 10, 1310-1315. http://dx.doi.org/10.1109/61.400910

[6] Schavemaker, P.H. and van der Sluis, L. (2000) An Improved Mayr Type Arc Model Based on Current-Zero Measurements. IEEE Transactions on Power Delivery, 15, 580-584. http://dx.doi.org/10.1109/61.852988

[7] Rong, M.Z., Yang, F., Wu, Y., Murphy, A.B., Wang, W.Z. and Guo, J. (2010) Simulation of Arc Characteristics in 
Miniature Circuit Breaker. IEEE Transactions on Plasma Science, 38, 2306-2311. http://dx.doi.org/10.1109/TPS.2010.2050703

[8] Wang, Q., Li, X.W., Chen, D.G. and Rong, M.Z. (2010) Simulation of the Venting Configuration Effects on Arc Plasma Motion in Low-Voltage Circuit Breaker. IEEE Transactions on Plasma Science, 38, 2300-2305.

http://dx.doi.org/10.1109/TPS.2010.2049382

[9] Dommel, H.W. (1986) EMTP Theory Book. Bonneville Power Administration, Portland. 